\title{
EXPERIMENTAL INVESTIGATION OF PROCESS OF PLASMA-ARC WIRE SPRAYING
}

\author{
I.P. GULYAEV ${ }^{1,2}$, P.Yu. GULYAEV ${ }^{2}$, V.N. KORZHIK ${ }^{3}$, A.V. DOLMATOV ${ }^{2}$, V.I. IORDAN $^{1,4}$, \\ I.V. KRIVTSUN ${ }^{3}$, M.Yu. KHARLAMOV ${ }^{3}$ and A.I. DEMIANOV ${ }^{3}$ \\ ${ }^{1}$ S.A. Khristianovich Institute of Theoretical and Applied Mechanics, SB RAS \\ 4/1 Institutskaya Str., 630090, Novosibirsk, RF \\ E-mail: admin@utam.nsc.ru \\ ${ }^{2}$ State University, Yugra \\ 16 Chekhov Str., 628012, Khanty-Mansiysk, Tyumen region, RF \\ E-mail: ugrasu@ugrasu.ru \\ ${ }^{3}$ E.O. Paton Electric Welding Institute, NASU \\ 11 Bozhenko Str., 03680, Kiev, Ukraine. E-mail: office@paton.kiev.ua \\ ${ }^{4}$ Altai State University \\ 61 Lenin Ave., 656049, Barnaul, Altai region, RF
}

\begin{abstract}
Application of current diagnostic systems becomes very important in development of fundamental concepts in area of thermal spraying and obtaining of new experimental data, in particular, on plasma-arc wire spraying. Firmware complex based on machine vision camera and digital spectrometer was proposed for experimental study of process of plasma-arc wire spraying of coatings. Procedure for experimental investigations of given process was developed. Results of measurements of velocity and temperature of dispersed phase particles as well as video of the most typical steps of plasma-arc spraying, including detachment of droplets from wire being sprayed and their breaking in plasma flow, were represented. Distribution of particles being sprayed in size was investigated and its effect on possibilities of temperature changes was analyzed. Experimental data obtained verified theoretical representations on types of flow and decomposition of jet of wire molten metal as well as droplet breaking in plasma jet. 18 Ref., 11 Figures.
\end{abstract}

$\boldsymbol{K} \boldsymbol{e} \boldsymbol{y} \boldsymbol{w} \boldsymbol{O} \boldsymbol{r} \boldsymbol{d} \boldsymbol{s}:$ thermal spraying, plasma-arc wire spraying, firmware complex, plasma flow, dispersed phase, for mation of drops of liquid metal, measurement of particle temperature, process visualization, spectral analysis

Development of methods for thermal spraying of coating is directly related with comprehensive investigations of physical and chemical processes, taking place in spraying. At that, namely experimental methods of investigations are of particular importance. They are the source of qualitative and quantitative data, promote development of fundamental ideas of thermal spraying processes as well as can be used as method for verification of theoretical approaches and mathematical models. The experiments receive particular importance in investigation of new, not enough studied methods, such as, for example, plasma-arc wire spraying [1] (PAWS).

Key peculiarity of this method is the fact that completely molten metal particles are entered into plasma flow, for example, in contrast to the processes of powder spraying, at which solidstate powder particles are entered in gas or plasma flow [2]. Obviously, that heat and dynamic interaction of dispersed phase with bearing flow is significantly different in cases of wire and powder spraying that has direct effect on structure and properties of produced coatings. In particular, large droplets of molten metal, moving in high-velocity plasma flow, are deformed; internal movement takes place in them, resulting in their breaking with formation of finer fragments [3]. It is sufficiently detailed information on phenomenology of processes of powder spraying, but there are virtually no experimental data on PAWS up to now. This is the basis for present work relevance.

All the systems widely used at present time for measurement of temperature and velocity of particles in thermal flows, namely DPV, Accuraspray (Tecnar, Canada), Spectraviz (Stratonics, USA), SprayWatch (Oseir, Finland), are based on realizing the methods of bichromatic pyrometery and time-of-flight method in that or another form [4, 5]. Besides, PIV (Particle Image Velocimetry) [6] and LDA (Laser-Doppler Anemometry) [7] methods are often used for velocity measurement. Cameras based on high-sensitive CCD and CMOS - matrices have good potential for development of the diagnostics systems. They allow registration of spatial distribution of particles with simultaneous measurement 
of their velocity and temperature. Such a system equipped with channel for registration of spectrum of optical radiation of hetero-phase flow allows increasing safety and accuracy of temperature measurements.

The matter of this work was development and testing of measurement complex, which, first of all, allows visualizing the process of formation and breaking of liquid metal droplets under conditions of PAWS, and, for the second, performing measurement of velocity and temperature characteristics of condensed phase particles [8, 9].

The investigations were carried out using machine for plasma-arc spraying of coatings PLAZER 30-PL-W with current-carrying wire. This machine is designed for deposition of wearresistant, corrosion-resistant and special coatings, repair of worn parts of machines by means of spraying of current-carrying materials in form of powder and compact wires of 1.6-2.0 $\mathrm{mm}$ diameter [1]. Appearance and scheme of experimental complex are presented in Figure 1.

Argon was used as plasma gas and compressed air was applied for plasma jet compression. Spraying of solid wire SV-08 from low-alloy steel was carried out in the following mode: arc current $220 \mathrm{~A}$, arc voltage $65-70 \mathrm{~V}$, argon consumption $28 \mathrm{l} / \mathrm{min}$, air consumption $330 \mathrm{l} / \mathrm{min}$, wire feed rate $14.7 \mathrm{~m} / \mathrm{min}$, wire diameter $1.6 \mathrm{~mm}$, and distance between the electrodes was $9 \mathrm{~mm}$. Plasmatron and wire feeder were located in spraying box (see Figure 1, $a$ ) close by which measurement equipment was mounted.

HD1-1312-1082-G2 camera (Photon Focus, Switzerland) and LR1-T digital spectrometer (ASEQ Instruments, Canada) were integrated in the experimental complex for investigation of dynamics and heat characteristics of the condensed phase at plasma-arc spraying. MATLAB media, having powerful means for transformation of multidimensional signals based on parallel computation technology, was used for data processing. Monochrome digital camera HD1-13121082-G2 is built on CMOS-matrix of $1312 \times 1082$ photo elements size with spectral sensitivity of 400-1000 nm range. Signal of its sensor is represented by 12-digit code and interface allows on-line transmitting full data into computer with 55 frames per second rate. Duration of frame exposure was varied from $10 \mu$ s to $10 \mathrm{~ms}$ range. Driver of the camera supports a standard interface of MATLAB media and gives the possibility of its application as a source at pipelined processing. Addition of SL-575-50 band filter ( $\mathrm{Fo}^{-}$ tooptic Ltd., Obninsk, RF) with central wavelength $575 \mathrm{~nm}$ and band width $50 \mathrm{~nm}$ (FWHM) to optical channel of HD1-1312-1082-G2 camera was necessary for performance of thermal imaging investigations. Moreover, correction of signal inhomogeneity of its sensor and calibration at automated bench, structure and functioning procedure of which are described in work [10], were also performed.

Digital spectrometer LR1-T is built on Czerny-Turner diagram, has linear CCD-probe with 3648 photo elements of $8 \times 200 \mu \mathrm{m}$ size and thermoelectric cooler for cooling to $-35{ }^{\circ} \mathrm{C}$ temperature, and can provide measurements in 200$1100 \mathrm{~nm}$ spectral range. Digital spectrometer data are represented by 16-digit code and they are transferred into computer via USB 2.0 interface. Receiving lens performed focusing of jet image at fiber optics endface of $200 \mu \mathrm{m}$ diameter, through which radiation was entered into device entrance slit. Time of spectrometer exposure varied in 10-100 ms range. M-class of aSpectr objects was developed for spectrometer integration in MATLAB media, which represents it in a form of virtual device with set of properties and methods. Measurement of temperature using spectral
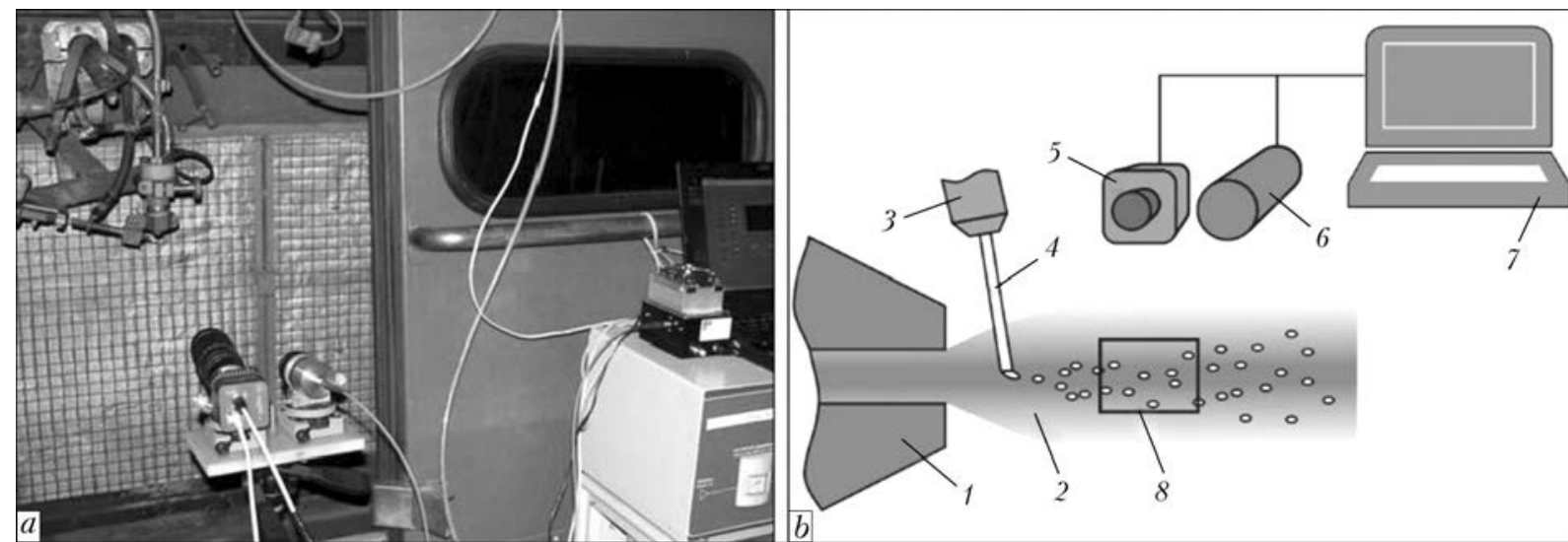

Figure 1. View $(a)$ and structure $(b)$ of diagnostic complex for investigation of process of PAWS: 1 - plasmatron; 2 - plasma jet; 3 - nozzle; 4 - wire being sprayed; 5 - camera; 6 - photospectrometer; 7 - computer; 8 test volume 


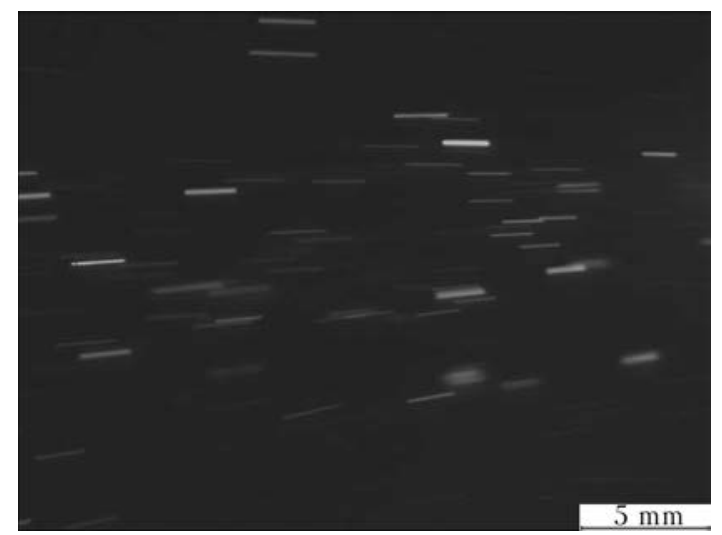

Figure 2. Initial frame showing tracks of particles of material being sprayed in jet sections $z=40-70 \mathrm{~mm}$ from nozzle edge

method was carried out by continuous (thermal) component of spectrum, free of line and banded radiation of atoms and molecules, in 550-600 nm range. For this preliminary correction of inhomogeneity of probe signal with the help of automated bench and procedure, described in work [11], was carried out.

Camera and receiving lens of the spectrometer were fastened to platform in such a way that their mutual positioning was constant (see Figure 1), and jet was in focus plane of both optical systems. Camera vision area covered part of the jet (test volume), size of which varied from $29 \times$ $\times 24$ to $68 \times 56 \mathrm{~mm}^{2}$. Area of spectrometer vision represented a circle of $10 \mathrm{~mm}$ diameter, located in the center of camera frame. Registration of wire melting, detachment and breaking of molten metal droplets in plasma flow was carried out in the initial imaging area not far from place of electric arc attachment to wire being sprayed. Measurement of temperature in this area was not carried out due to strong plasma radiation. Further the platform with camera and lens was moved along plasma jet, providing successive overlapping of areas of temperature and particle velocity measurement.

Figure 2 shows initial (unprocessed) frame of plasma jet with particle tracks. A mask was made for each frame of video stream, and morphological analysis was carried out. During analysis the frame was divided in objects, corresponding to separate possible tracks. Each separated object

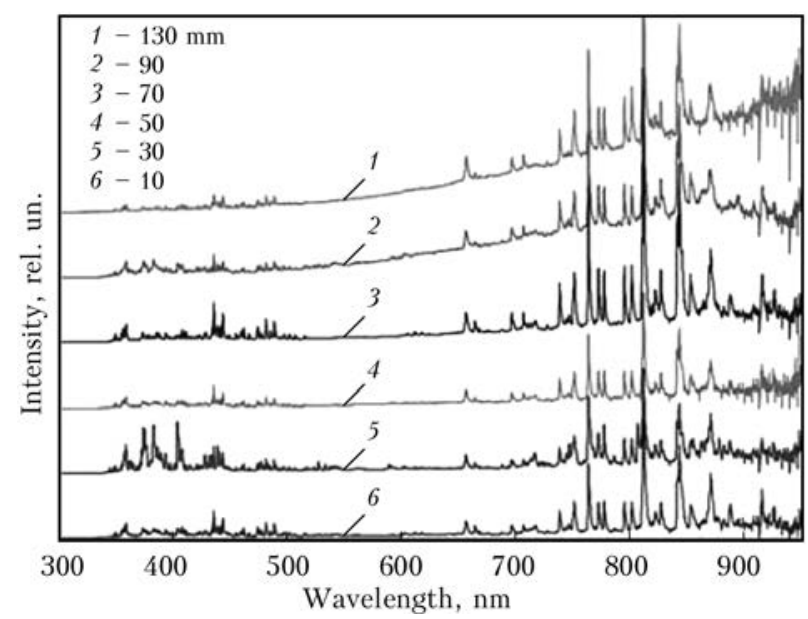

Figure 3. Spectra of radiation of plasma jet at different distances from nozzle edge

was analyzed from point of view of determination of visible diameter of the particle, track length, coordinates of its center, orientation and brightness. In order to eliminate objects corresponding to «splicing» of tracks, filtering on length, diameter and relationship of maximum to average brightness were carried out [12].

Figure 3 shows the spectra of plasma jet radiation registered at $z=10-130 \mathrm{~mm}$ distance from plasmatron nozzle edge. Spectrum range of $550-600 \mathrm{~nm}$, free of own radiation of plasma, was selected, based on obtained data, for temperature measurement by brightness (camera) and spectrum methods. A new approach was used for determination of particle temperature distribution. It lies in registration by photo-spectrometer of total radiation of ensemble of particles, which passed the test volume during device exposure time, and further reconstruction of particle temperature distribution using mathematical method [13, 14].

Visualizing the process of melt formation and droplet detachment from the end of wire being sprayed as well as movement and breaking of particles at the initial part of jet are still one of the main investigation tasks.

Earlier mathematical modelling [15] determined that plasma-arc spraying can have three types of flow and decomposition of jet of wire molten metal, namely, jet metal flow, formation

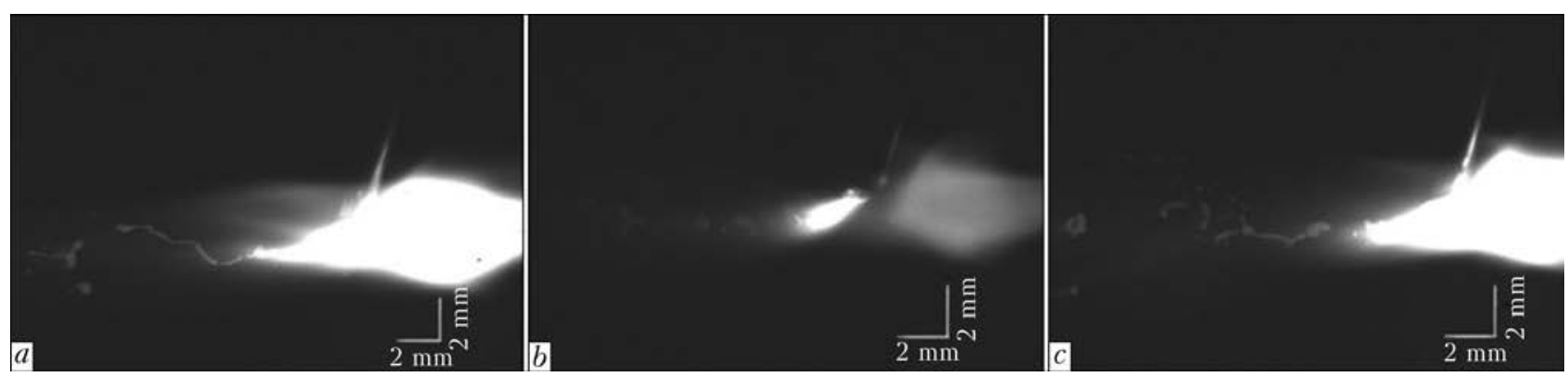

Figure 4. Visualizing droplet detachment from end of wire being sprayed; $a$ - jet metal flow; $b-$ formation of droplets similar in size; $c$ - formation of droplets having significant differences in size 
of droplets of virtually similar size, and, at least, formation of droplets having significant difference in size. Images, represented in Figure 4, completely correspond to given conclusions.

Thus, analysis of images shows (Figure $4, b$ ) that melt, formed at the end of spray wire at optimum spraying mode, is stretched in 3-4 mm length filament, which is decomposed on virtually similar droplets of $650-700 \mu \mathrm{m}$ diameter. Transfer modes of machine operation (switching on, adjustment of arc current, gas consumption or rate of wire feed) can show jet flow of molten metal without actual spraying, as represented in Figure 4, $a$, where filament length makes 11$12 \mathrm{~mm}$. And, finally, Figure 4, $c$ shows spraying mode with droplet formation having significant difference in size, which can be observed at wrong selection of wire feed rate. In this case, periodic change of length of formed metal filament and, respectively, size of detached droplets take place. At that, detachment of large droplets $(\sim 900 \mu \mathrm{m}$ and more) is accompanied by formation of finer droplet-satellites $(\sim 100 \mu \mathrm{m})$.

Obtained experimental results show that initial droplets start intensive breaking virtually at once after detachment from the wire end. This process takes place in area of 50-60 $\mathrm{mm}$ from the end of wire being sprayed. At that, the following types of droplet breaking are typical under conditions of plasma-arc spraying (Figure 5), namely, breaking for several large droplets, breaking by «parachute» type, and «parachute» with filament [3]. In particular, Figure 5, $a$ shows the moment preceding breaking of large droplet for two smaller fragments. Figure 5, $b$ illustrates the moment of fragments spread in breaking by «parachute» mode, i.e. number of fine droplets is formed at breaking of blown «pocket» as well as larger dropletsat - edge breaking.

Quenching of particles being sprayed was carried out in a basin with water at $200 \mathrm{~mm}$ distance from plasmatron nozzle for measurement of their size. Produced powder was investigated using laser-diffraction particle size analyzer LS13 320 (Beckman Coulter, USA). The results are represented in Figure 6. Spectrum of material particle size is very wide, i.e. from $400 \mathrm{~nm}$ to $400 \mu \mathrm{m}$, that can be explained by active breaking and evaporation of liquid particles in the initial area of plasma jet. Overwhelming majority of the particles are of small (no more than 2-3 $\mu \mathrm{m}$ ) size, and, at the same time, their mass fraction is negligibly small. Two significant facts should be noted from practical point of view: first, droplets of $50-400 \mu \mathrm{m}$ size represent the main mass of material particles, forming the coating; second, total area of surface of particles is uniformly distributed among droplets of $500 \mathrm{~nm}$ to $200 \mu \mathrm{m}$ size, therefore, particles of fine fractions, having the highest temperature, will
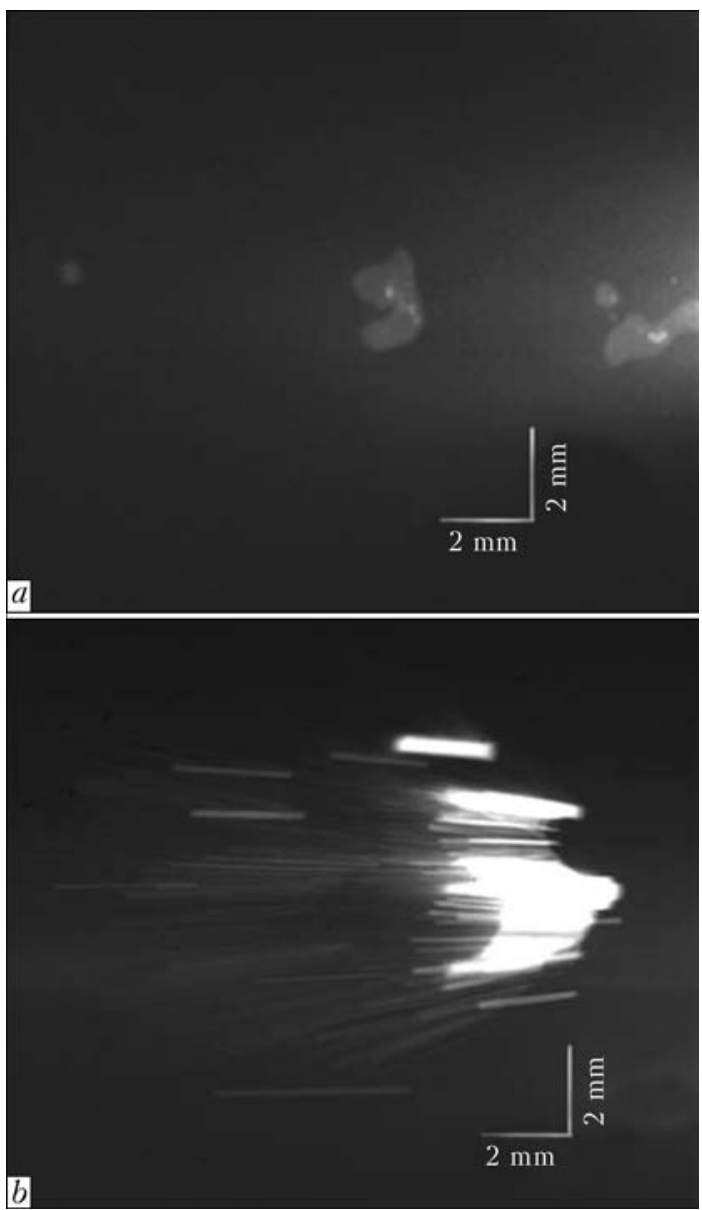

Figure 5. Breaking of droplets of molten metal in plasma flow: $a$ - breaking for several large droplets; $b-$ «parachute» type of breaking

make the main contribution in general spectrum of heat emission of particles.

Local distributions of given parameters in the jet volume were reconstructed based on results of measurement of velocity and temperature of separate particles. The whole volume of sampling made 60,000 of identified objects. For example, Figures 7 and 8 show statistical histograms of distribution of particle velocity and temperature in jet section $z=160 \mathrm{~mm}$ from nozzle edge. Dashed lines indicate average $V_{\mathrm{av}}$ and $T_{\mathrm{av}}$ values

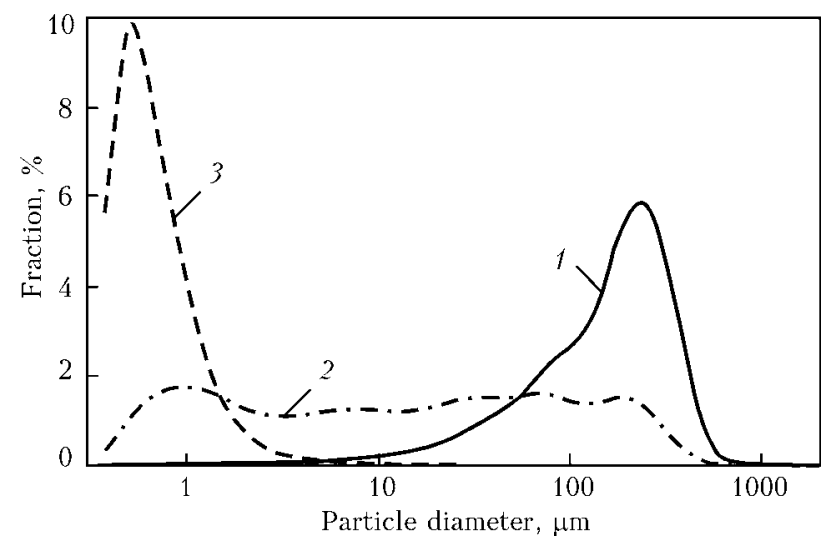

Figure 6. Size distribution of particles of spray material: 1 - mass; 2 - area; 3 - number of particles 


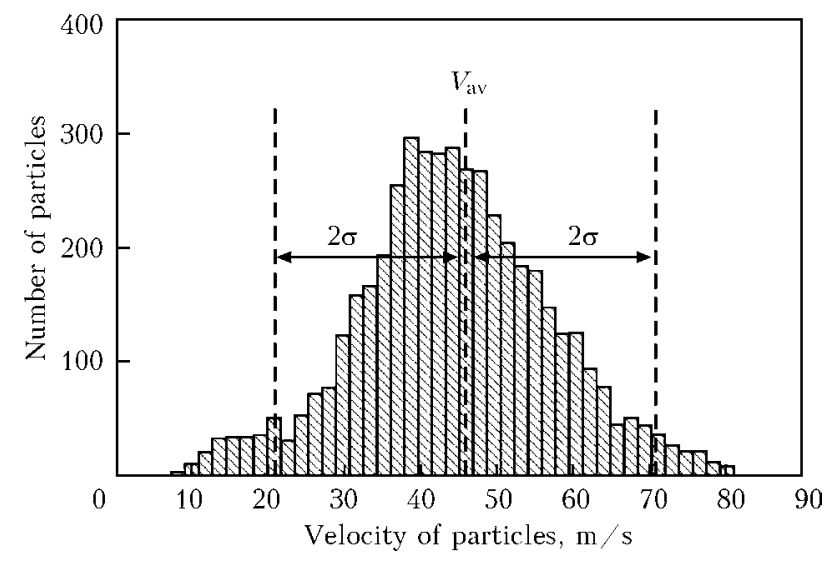

Figure 7. Distribution of particle velocities in jet section $z=160 \mathrm{~mm}$

as well as boundaries of $V_{\mathrm{av}} \pm 2 \sigma$ and $T_{\mathrm{av}} \pm 2 \sigma$ ranges, where $\sigma$ is the standard deviation from corresponding average value.

Figure 9 shows a change of average particle velocity $V_{\text {av }}$ in movement along the jet. It can be indicated that $V_{\mathrm{av}}$ value reaches fixed level of $45-50 \mathrm{~m} / \mathrm{s}$ at $100-160 \mathrm{~mm}$ distance from the nozzle. At that, spread of particle velocities is sufficiently large, i.e. $2 \sigma=22-25 \mathrm{~m} / \mathrm{s}$, that is a half of $V_{\text {av }}$ value. This is related with wide range of sizes of the particles, formed under conditions of PAWS.

Figure 10 gives the results of measurement of particle temperature in different sections of the jet, received by brightness (camera) and spectral methods. As can be seen, obtained temperature values have significant difference that can be explained in the following way. Algorithm applied for processing of still images does not include recognizing the particles, image of which has subpixel size. This means that only particles of more than $50 \mu \mathrm{m}$ size are identified using selected $51.9 \mu \mathrm{m} /$ pixel spatial resolution of video system. Therefore, temperatures of dispersed phase, measured by brightness method, correspond exactly to that large particles, from which the coating is mainly formed. As can be seen, average

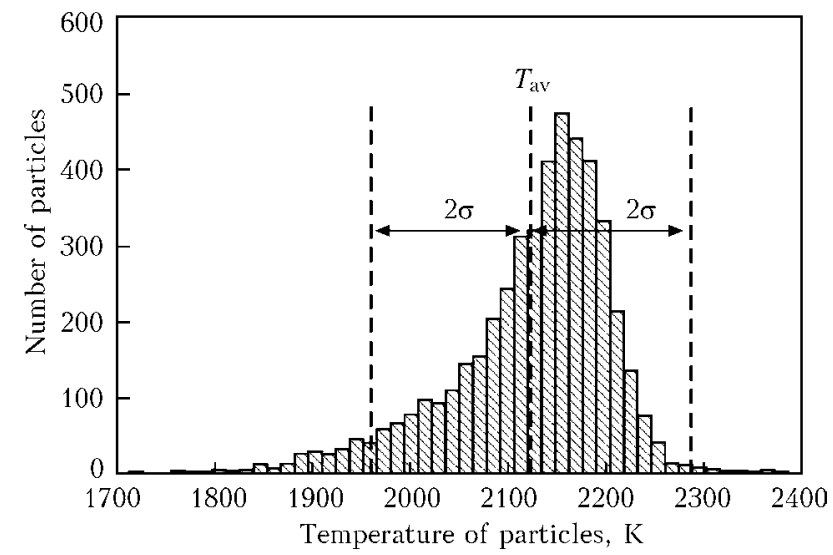

Figure 8. Distribution of particle temperatures in section $z=160 \mathrm{~mm}$

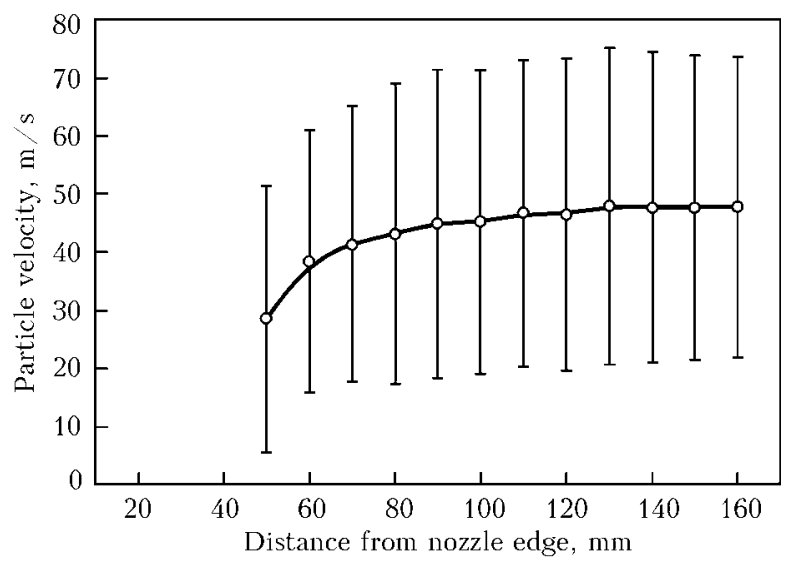

Figure 9. Value of average velocity of particles in different jet sections

temperature of particles gradually increases (from 2000 to $2130 \mathrm{~K}$ ) along the spraying distance. This is related with the fact that initial temperature of droplets at once exceeds melting temperature and makes $1700-1800 \mathrm{~K}$ in contrast to powder spraying.

On the other hand, spectral method always provides for the result close to maximum distribution temperature [16] in the case of presence of inhomogeneous temperature field in area of observation. It is obvious fact that the particles of the smallest size, which are quickly heated by bearing plasma flow, will have the maximum temperature in the initial jet area. Typical time of particle heating-up is of $\tau \sim d^{2} / a$ order (where $d$ is its diameter, $a$ is the temperature conductivity of its material), that, for steel droplet of $1 \mu \mathrm{m}$ diameter, for example, provides for $1 \mu \mathrm{s}$ value. Considering the fact that such fine particles move with $V \approx 100 \mathrm{~m} / \mathrm{s}$ velocity, they can be assumed as «heat markers», temperature of which equals local temperature of plasma flow in area of $\delta=\tau V$, i.e. around $100 \mu \mathrm{m}$. It should be mentioned here that such an approach is used for measurement of temperature of flame, in which superdispersed soot particles being a heat radiation source are formed [17, 18].

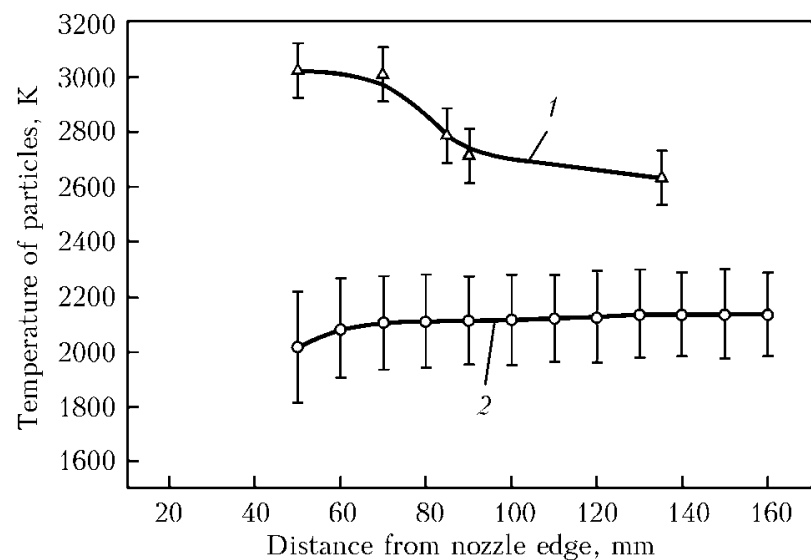

Figure 10. Value of average temperature of particles in different jet sections: 1 - spectral measurements; 2 brightness measurements 
It can be seen in Figure 10 that temperature of the particles measured by spectral method is monotonously reduced in removal from plasmatron nozzle edge. Its maximum values in initial area do not exceed temperature of steel boiling (3000-3100 K), since further metal overheating requires larger heat input. Ultra-fine particles due to their small mass are taken out of the limits of jet core by expanding plasma flow, where plasma temperature is reduced.

Plasma own intensive radiation did not allow measuring temperature of dispersed phase by spectral and brightness methods in area of electric arc attachment to wire being sprayed. However, results of this area visualizing, given in $\mathrm{Fi}$ gure 11, are interesting. Bright radiation of plasma flow, the most heated area of steel wire, i.e. anode spot, as well as separate droplet of melt, flowed by high-velocity plasma jet, can be observed. Clear aerodynamic path is noted down the flow following the droplet, which is, possibly, visualized due to material evaporation. Thus, intensive heating of particles up to material melting temperature takes place already at $\sim 8 \mathrm{~mm}$ distances from wire being sprayed $(\sim 15 \mathrm{~mm}$ from plasmatron nozzle edge).

Experimental complex was developed for investigation of processes of heat and dynamic interaction of liquid particles with plasma flow under conditions of PAWS of coatings. HD11312-1082-G2 camera and LR1-T spectrometer make a basis of complex measurement equipment. Thermal imagining system allowed visualizing processes of melt formation, detachment of metallic droplets and their further breaking as well as carrying out measurements of velocity and temperature of particles along the spraying distance. Using channel for registration of radiation spectrum of heterophase jet allowed making grounded selection of working spectral range of the camera. Analysis of distribution of material particles by size showed that measurements of temperature by spectral method reflected local temperature of bearing plasma flow. Experimental data verified obtained earlier theoretical formulations on types of flow and decomposition of molten wire metal as well as variants of droplet breaking in the plasma jet.

The work is carried out in scope of joint project RFFI (No. 14-08-90428) and NAS of Ukraine (No. 06-08-14).

1. Korzhik, V.N., Kharlamov, M.Yu., Petrov, S.V. et al. (2011) Technology and equipment of plasma-arc spraying for repair of critical parts of railway transport. Vestnik V. Dal VUNU, 14, 76-82.

2. Pawlowski, L. (2008) Science and engineering of thermal spray coatings. 2nd ed. John Wiley \& Sons.

3. Nigmatulin, R.I. (1987) Dynamics of multiphase me dia. Pt 1. Moscow: Nauka.

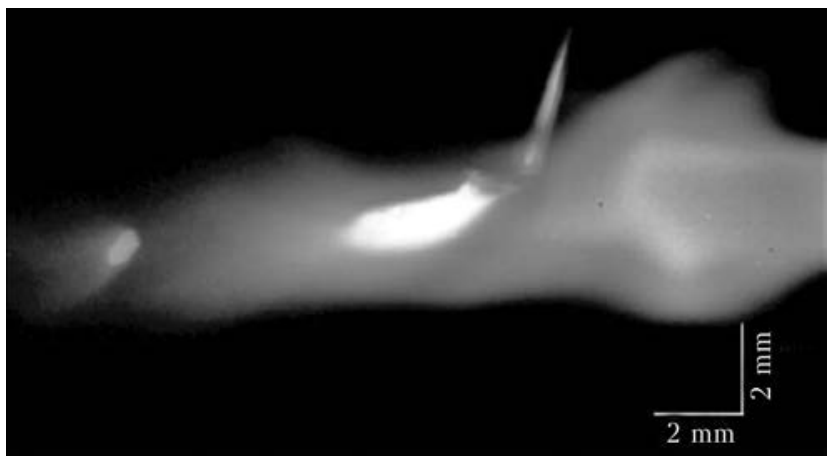

Figure 11. Visualizing the process of material evaporation from surface of droplets detached from wire being sprayed

4. Mauer, G., Vassen, R., Stoever, D. (2007) Comparison and applications of DPV-2000 and accura-sprayg3 diagnostic systems. J. Thermal Spray Technology, $16(3), 414-424$

5. Schwenk, A., Wank, A., Wallendorf, T. et al. (2010) NIR (Near-Infra-Red) sensor - An alternative diagnostic tool for the online process control of thermal spray processes. In: Proc. of Int. Thermal Spray Conf. (Singapore, 2010), 120-123.

6. Marchand, O., Bertrand, G., Planche, M.P. (2009) Particle image velocimetry diagnostics for suspension plasma spraying. In: Proc. of Int. Thermal Spray Conf. (4-5 May, 2009, Las Vegas, USA), 855-860.

7. Zimmermann, S., Vogli, E., Kauffeldt, M. et al. (2010) Supervision and measuring of particle parameters during the wire-arc spraying process with the diagnostic systems Accuraspray-g3 and LDA. (LaserDoppler-Anemometry). J. Thermal Spray Technology, 19(4), 745-755.

8. Boronenko, M.P., Gulyaev, I.P., Gulyaev, P.Yu. et al. (2013) Methods of control of temperature and velocity of condensed phase particle during plasma-arc spraying. Fundament. Issledovan., 10(6), 1194-1199.

9. Gulyaev, P.Yu., Dolmatov, A.V., Popov, V.A. et al. (2012) Methods of optical diagnostics of particles in hightemperature flows. Polzunozsky Vestnik, 1/2, 4--7.

10. Dolmatov, A.V., Ermakov, K.A., Lavrikov, V.V. et al. (2012) Complex of automated calibration of thermal image system on the base of MATLAB. Vestnik YugorskGU, 25(2), 59-63.

11. Dolmatov, A.V., Gulyaev, I.P., Imamov, R.R. (2014) Spectral pyrometer for control of temperature in process of thermosynthesis. Ibid., 33(2), 32-42.

12. Boronenko, M.P., Gulyaev, I.P., Gulyaev, P.Yu. et al. (2014) Evaluation of velocity and temperature of dispersed phase in plasma-arc spraving jets. Fundament. Issledovan., 10(11), 2135-2140.

13. Gulyaev, I.P., Solonenko, O.P., Smirnov, A.V. et al. Method for determination of temperature distribution of condensed phase particles in two-phase plasma flow. Pat. $2383873 \mathrm{RF}$. Int. Cl.G01J $3 / 30$. Publ. 10.03.2010.

14. Gulyaev, I.P. Ermakov, K.A., Gulyaev, P.Yu. (2014) New high-speed combination of spectroscopic and brightness pyrometry for studying particles temperature distribution in plasma jets. Europ. Researcher, 71(3/2), 564-570.

15. Kharlamov, M.Yu., Krivtsun, I.V., Korzhyk, V.N. (2014) Dynamic model of the wire dispersion process in plasma-arc spraying. J. Thermal Spray Technology, 23(3), 420-430.

16. Magunov, A.N. (2010) Spectral pyrometry of objects with inhomogeneous temperature. Zhurnal Tekhnich. Fiziki, 80(7), 78-82.

17. Zhao, H., Ladommatos, N. (1998) Optical diagnostics for soot and temperature measurement in diesel engines. Progress in Energy and Combustion Sci., 24(3), 221-255.

18. Lu, G., Yan, Y. (2006) Temperature profiling of pulverized' coal flames using multicolor pyrometric and digital imaging techniques. IEEE Transact. on Instrumentation and Measurement, 55(4), 1303-1308. 